\title{
Adverse Health Effects Associated with Living in a Former Methamphetamine Drug Laboratory - Victoria, Australia, 2015
}

\author{
Jackie Wright, $\mathrm{PhD}^{1}$; Michaela E. Kenneally ${ }^{2}$; John W. Edwards, $\mathrm{PhD}^{1}$; G. Stewart Walker, $\mathrm{PhD}^{3}$
}

The manufacture of methamphetamine in clandestine drug laboratories occurs in various locations, including residential houses and apartments. Unlike the controlled manufacture of chemicals and drugs, clandestine manufacture results in the uncontrolled storage, use, generation, and disposal of a wide range of chemicals and the deposit of methamphetamine drug residues on indoor surfaces (1). These residues have been found at high levels on porous and nonporous surfaces and have been shown to persist for months to years (1). Persons exposed to these environments often have poorly defined exposures and health effects. It is commonly assumed that these levels of exposure are low compared with those related to illicit drug use or therapeutic use of amphetamine-based drugs for managing behavioral issues such as attention deficit hyperactivity disorder (2). In 2015, a family that was unknowingly exposed to methamphetamine residues in a house in Australia was found to have adverse health effects and elevated methamphetamine levels in hair samples, highlighting the potential for public health risks for persons who might live in methamphetaminecontaminated dwellings. This case study highlights the importance of the identification and effective decontamination of former clandestine drug laboratories.

In May 2013, police seized chemicals and manufacturing equipment from a property in rural Victoria, Australia, and arrested the owner. After completing investigation of the property, police issued a notice to the local council indicating that the property was a former clandestine drug laboratory and posed a potential health risk. The council issued a notice to clean up the property; however, the cleanup was not performed. The property was sold in August 2013, and normal prepurchase checks did not identify the property as a former methamphetamine laboratory or reveal that a notice to clean up the house had been issued. In October 2013, the new owners, a family of five, moved into the house. Seven months later, in May 2014, the local council contacted the owners to advise them that their home was a former drug laboratory. Environmental testing of the home was carried out during late May-October 2014 and revealed elevated levels of methamphetamine on surfaces inside the home, ranging from $11.7-26.0 \mu \mathrm{g} / 100 \mathrm{~cm}^{2}$, well above the Australian limit of $0.5 \mu \mathrm{g} / 100 \mathrm{~cm}^{2}$ (3) for safe levels in a residential home. The family was required to vacate the property in March 2015.

The family included two adults and three children aged 7,8 , and 11 years. None of the family members had ever used methamphetamine or had been taking any prescribed amphetamine-based medications. Data concerning health effects were obtained from documentation of medical assessments from the family doctor, school medical information, self-reported observations by the family members in response to a questionnaire, and evaluation of behavioral issues, based on the completion of the Behavior Assessment System for Children, Second Edition (BASC-2)* Parent Rating Scales (PRS).

Assessment of drug exposure levels was based on the collection and analysis of hair samples from all members of the family 1 week after leaving the home, and from the children, approximately 3 months later. Because none of the family members used amphetamines, through either prescription or illicit drug use, the testing of hair to determine environmental exposure was considered suitable. Hair samples measuring 3-4 cm in length (from the scalp) were collected, which was considered representative of exposure over the 3-4 months preceding sampling. Testing of the hair was conducted at Forensic Science, South Australia by methanolic extraction and analysis of the extract by liquid chromatography with tandem mass spectrometry using electrospray ionization. The hair was subjected to a methanol wash before extraction to remove any recent external contamination. The washes also were analyzed for the presence of amphetamines. The lower limit of detection for this analysis was $5 \mathrm{pg} / \mathrm{mg}$ for methamphetamine and amphetamine.

All family members experienced adverse health effects while living in the home. The most serious health effects were reported in the youngest child (a boy aged 7 years) and included development of asthma-like symptoms, trouble sleeping, and behavior changes (Table 1). Of note, a parent-requested cognitive behavioral assessment to evaluate potential gifted traits, undertaken for this child 3 months before moving into the home identified no at-risk or clinically significant behavioral issues. From the BASC-2 PRS evaluation conducted 1 week after moving out of the home, anxiety, attention issues, and somatization were scored as at-risk or clinically significant and were consistent with observations provided by the mother and school personnel. Most of the health problems identified in all family members, including the youngest child, were observed to resolve over time (6-12 months) after they were moved from the contaminated premises (Table 1).

Methamphetamine was detected in the hair of all family members at concentrations ranging from 5 to $460 \mathrm{pg} / \mathrm{mg}$

*http://www.pearsonclinical.com/education/products/100000658/behaviorassessment-system-for-children-second-edition-basc-2.html. 
(Table 2). Amphetamine was also detected in the hair of the two youngest children, ranging from 16 to $20 \mathrm{pg} / \mathrm{mg}$ (Table 2). The highest methamphetamine levels in the hair samples collected were found in the two youngest children (boys aged 7 and 8 years), with a lower level $(50 \mathrm{pg} / \mathrm{mg})$ found in the hair of the older child, a girl aged 11 years.

Lower levels of methamphetamine were reported in the hair of the children's mother $(17 \mathrm{pg} / \mathrm{mg})$ and father $(5 \mathrm{pg} / \mathrm{mg})$. The only detection of methamphetamine in the hair wash was from the mother $(8 \mathrm{pg} / \mathrm{mg})$.

Retesting for drugs in hair samples 3 months after moving out of the home (June 2015), indicated clearance of the drug, with no detection of amphetamines in the hair for most family members. Methamphetamine $(60 \mathrm{pg} / \mathrm{mg})$ was reported in the hair sample of the boy aged 8 years and was thought to be related to differences in hair growth rate and hair sample collection.

\section{Discussion}

The data from this case study of a single family present evidence of adverse health effects and reflect exposure to methamphetamine that occurred while living in a home with environmental methamphetamine surface contamination levels in the range of $11.7-26.0 \mu \mathrm{g} / 100 \mathrm{~cm}^{2}$.

The highest levels of methamphetamine detected in the hair samples analyzed were from the two younger children. These children had the lowest body weights in the family

TABLE 1. Adverse health effects reported by family members while living in and after vacating a methamphetamine-contaminated house Victoria, Australia, 2015

\begin{tabular}{|c|c|c|c|c|}
\hline Age (yrs) & Sex & Respiratory & Cognitive/Behavioral & Other adverse health effects \\
\hline 7 & Male & $\begin{array}{l}\text { Persistent cough, asthma- } \\
\text { like symptoms }\end{array}$ & $\begin{array}{l}\text { Trouble sleeping, fearfulness, vivid/scary dreams, irritability, } \\
\text { aloof, easily distracted. BASC-2 testing: anxiety, somatization, } \\
\text { ADHD (at-risk or clinically significant; not present before living } \\
\text { in home) }\end{array}$ & Skin rashes; sore, watery eyes \\
\hline 8 & Male & Asthma & $\begin{array}{l}\text { BASC- } 2 \text { testing: no issues identified } 1 \text { week after vacating } \\
\text { home; anxiety and somatization reported } 3 \text { months after } \\
\text { vacating home, while living in rented accommodation without } \\
\text { access to personal possessions }\end{array}$ & Sore, watery eyes \\
\hline 11 & Female & Persistent cough & $\begin{array}{l}\text { Trouble sleeping, irritability. BASC-2 testing: no significant } \\
\text { issues identified }\end{array}$ & Sore, watery eyes \\
\hline 40 & Female & Persistent cough & Excess energy & $\begin{array}{l}\text { Sore, watery eyes; weight loss; } \\
\text { improved distance vision }\end{array}$ \\
\hline 38 & Male & none & Trouble sleeping, decreased memory function (self-reported) & $\begin{array}{l}\text { Sore, watery eyes; dizziness and } \\
\text { blurry vision while cleaning } \\
\text { contaminated areas }\end{array}$ \\
\hline
\end{tabular}

Abbreviations: BASC-2 = Behavior Assessment System for Children, Second Edition; ADHD = attention deficit hyperactivity disorder.

TABLE 2. Concentrations of methamphetamine and amphetamine in hair samples collected from members of a family exposed to a methamphetamine-contaminated residence 1 week and 3 months after vacating the home - Victoria, Australia, 2015

\begin{tabular}{|c|c|c|c|c|c|c|}
\hline \multirow[b]{2}{*}{ Age (yrs) } & \multirow[b]{2}{*}{ Sex } & \multicolumn{2}{|c|}{$\begin{array}{l}\text { Concentrations at } 1 \text { week after } \\
\text { vacating the home }(\mathrm{pg} / \mathrm{mg})\end{array}$} & \multicolumn{2}{|c|}{$\begin{array}{l}\text { Concentrations at } 3 \text { months after } \\
\text { vacating the home }(\mathrm{pg} / \mathrm{mg})\end{array}$} & \multirow{2}{*}{$\begin{array}{c}\text { Factors that might increase or decrease } \\
\text { exposure in the home }\end{array}$} \\
\hline & & Methamphetamine & Amphetamine & Methamphetamine & Amphetamine & \\
\hline 7 & Male & 460 & 20 & Not detected & Not detected & $\begin{array}{l}\text { Regularly played games that involved rolling } \\
\text { on the floor, touching all surfaces and }\end{array}$ \\
\hline 8 & Male & 330 & 16 & 60 & Not detected & $\begin{array}{l}\text { running hands along the walls. Infrequent } \\
\text { washing of hands. }\end{array}$ \\
\hline 11 & Female & 50 & Not detected & Not detected & Not detected & $\begin{array}{l}\text { Spent a lot of time on electronic media and } \\
\text { limited active play with brothers. }\end{array}$ \\
\hline 40 & Female & $17^{*}$ & Not detected & Not tested & Not tested & $\begin{array}{l}\text { Regularly cleaned the home, including just } \\
\text { before hair samples were collected. Has } \\
\text { colored hair. }\end{array}$ \\
\hline 38 & Male & 5 & Not detected & Not tested & Not tested & $\begin{array}{l}\text { Works out of the home most of the day, } \\
\text { including weekends. }\end{array}$ \\
\hline
\end{tabular}

* Methamphetamine $(8 \mathrm{pg} / \mathrm{mg}$ ) also was detected in the methanol wash of this hair sample. 
and, according to their parents, had multiple opportunities for regular close contact with indoor surfaces, including engaging in activities that involved rolling on the floor, running around the house, rubbing their hands on walls, and touching items throughout the home. In addition, these children were reported by their parents to wash their hands less frequently than other members of the family. The oldest child reportedly spent more time using electronic media and was involved in limited physical play; her hair methamphetamine level was substantially lower than those of her two brothers.

The lower levels of methamphetamine reported in the hair of the mother potentially reflect lower levels of methamphetamine exposure in the home. In addition, the mother reported that she colored her hair, which has been reported to result in some loss of amphetamine in tested hair samples $(4,5)$. The children's mother reported regularly cleaning the house, including just before hair sampling after moving out of the home. This might account for a measured level of methamphetamine identified in the extract from the external hair wash. The children's father worked away from the home most of the day; his hair had the lowest level of methamphetamine contamination.

Methamphetamine levels in the hair samples of the two younger children ( $460 \mathrm{pg} / \mathrm{mg}$ and $330 \mathrm{pg} / \mathrm{mg}$ ) are consistent with the lower end of the range reported in children removed from clandestine drug laboratories $($ range $=100 \mathrm{pg} / \mathrm{mg}-131,000 \mathrm{pg} / \mathrm{mg})(6,7)$ and chronic adult drug users (range $=100 \mathrm{pg} / \mathrm{mg}-128,000 \mathrm{pg} / \mathrm{mg}$ ) $(6,8)$. The levels reported were similar to those reported in studies conducted on low-level methamphetamine use by adults smoking doses of approximately $500-1,000 \mathrm{mg} /$ day (8). The detection of amphetamine in the hair of the younger children might reflect environmental exposures in the home, where low levels of amphetamine also were detected in the surface samples analyzed (but not quantified by the laboratory), or the presence of metabolites, supporting the systemic absorption of methamphetamine. The ratio of methamphetamine to amphetamine in the hair was found to be consistent with the mean reported in hair samples from children removed from clandestine drug laboratories and from drug-exposed children $(6,7)$.

The most substantial health effects were in the youngest child, who also had the highest measured levels of methamphetamine in hair. The health effects reported in this study also have been reported in children removed from active methamphetamine drug laboratories (9). Follow-up with the family has identified that the respiratory effects, trouble sleeping, and behavioral changes mostly resolved during the 12 months after the family vacated the contaminated home.

The findings in this report are subject to at least two limitations. First, there is no established quantitative relationship between the dose of methamphetamine to which a person is exposed and the measured methamphetamine level in hair. In addition, there

\section{Summary \\ What is already known about this topic?}

The clandestine manufacture of methamphetamine is known to result in various levels of contamination of all surfaces in homes. Information is available on drug exposures and health effects for drug users as well as persons exposed during manufacture.

What is added by this report?

A family of five, including three children aged 7-11 years, lived in a home in rural Victoria, Australia, that was previously a clandestine methamphetamine drug laboratory with documented environmental contamination. The family members developed adverse health effects, and there was evidence of systemic absorption of methamphetamine from the environment, based on hair samples collected after they had vacated the premises. Health effects were most pronounced in the youngest child, who also had the highest methamphetamine levels in hair, possibly related to a combination of repeated contact with surfaces during play activities and less frequent hand washing.

What are the implications for public health practice?

If properties formerly used for the clandestine manufacture of methamphetamine are not properly cleaned the public might be unknowingly exposed to drug residues. Appropriate identification and management of these properties, including measures by authorities to prevent the sale of unremediated homes, are important to prevent exposures and adverse health effects.

is significant variation among persons who might have had the same level of exposure and the measured levels in hair, although for an individual, correlation between dose and the concentration of amphetamines in hair has been reported $(8,10)$. However, the data reported for the family members support the association of higher levels of methamphetamine and amphetamine in hair with higher levels of exposure (based on reported activities, body weight, and time in the contaminated home). The fact that hair concentrations declined precipitously after the exposure was removed is consistent with an association between exposure and elevated hair levels. Second, the presence of methamphetamine and amphetamine in the hair samples collected reflect exposures that might have occurred during the preceding 3-4 months (10) with the environmental data (surface residue sampling) reflecting contamination levels at the time of sampling only (approximately 3-6 months before the collection of hair samples). Levels of environmental contamination and exposures that might have occurred before this time are not known and might have been higher.

Residual environmental methamphetamine contamination can result in adverse health effects in exposed persons, particularly in young children. Appropriate identification and management of former clandestine drug laboratories, including appropriate remediation and measures to prevent the sale of contaminated homes, is important to prevent exposures and adverse health effects. 
${ }^{1}$ Health and Environment, School of the Environment, Flinders University, Adelaide, South Australia, Australia; ${ }^{2}$ Toxicology, Forensic Science SA, Government of South Australia, Adelaide; ${ }^{3}$ School of Chemical \& Physical Sciences, Flinders University, Adelaide, South Australia, Australia.

Corresponding author: Jackie Wright, jackie@enrisks.com.au.

\section{References}

1. Martyny JW, Arbuckle SL, McCammon CS Jr, Esswein EJ, Erb N, Van Dyke M. Chemical concentrations and contamination associated with clandestine methamphetamine laboratories. J Chem Health Saf 2007;14:40-52. http://dx.doi.org/10.1016/j.jchas.2007.01.012

2. Weisheit R. Making methamphetamine. South Rural Sociol 2008;23:78-107.

3. Australian Government. Clandestine drug laboratory remediation guidelines. Canberra, Australia: Commonwealth of Australia; 2011. https://www.ag.gov.au/CrimeAndCorruption/Drugs/Documents/ Clandestinedruglaboratoryremediationguidelines.pdf

4. Baeck S, Han E, Chung H, Pyo M. Effects of repeated hair washing and a single hair dyeing on concentrations of methamphetamine and amphetamine in human hairs. Forensic Sci Int 2011;206:77-80. http:// dx.doi.org/10.1016/j.forsciint.2010.06.023
5. Tsanaclis L, Wicks JF. Patterns in drug use in the United Kingdom as revealed through analysis of hair in a large population sample. Forensic Sci Int 2007;170:121-8. http://dx.doi.org/10.1016/j.forsciint.2007.03.033

6. Bassindale T. Quantitative analysis of methamphetamine in hair of children removed from clandestine laboratories - evidence of passive exposure? Forensic Sci Int 2012;219:179-82. http://dx.doi. org/10.1016/j.forsciint.2012.01.003

7. Castaneto MS, Barnes AJ, Scheidweiler KB, et al. Identifying methamphetamine exposure in children. Ther Drug Monit 2013;35:823-30. http://dx.doi.org/10.1097/FTD.0b013e31829685b2

8. Han E, Paulus MP, Wittmann M, Chung H, Song JM. Hair analysis and self-report of methamphetamine use by methamphetamine dependent individuals. J Chromatogr B Analyt Technol Biomed Life Sci 2011;879:541-7. http://dx.doi.org/10.1016/j.jchromb.2011.01.002

9. Wright J, Edwards J, Walker S. Exposures associated with clandestine methamphetamine drug laboratories in Australia. Rev Environ Health 2016;31:329-52. http://dx.doi.org/10.1515/reveh-2016-0017

10. Polettini A, Cone EJ, Gorelick DA, Huestis MA. Incorporation of methamphetamine and amphetamine in human hair following controlled oral methamphetamine administration. Anal Chim Acta 2012;726:35-43. http://dx.doi.org/10.1016/j.aca.2012.01.042 